\title{
Strengthening of RC Square Column using Stainless Steel Wire Mesh
}

\author{
Iyappan. G.R ${ }^{1}$, Dr. D. Elango ${ }^{2}$ \\ ${ }^{1}$ Assistant Professor, Valliammai Engineering College, Kattankulathur, India \\ ${ }^{2}$ Professor\& Head, Valliammai Engineering College, Kattankulathur, India
}

\author{
*Corresponding Author: Dr. D. Elango, Professor and Head, Valliammai Engineering College, Kattankulathur. \\ India.
}

\begin{abstract}
The capacity of existing columns needs to be increased when there is an increase in applied load beyond the design load. Retrofitting is considered as more economic and time consuming technique as compared to reconstruction. This paper deals with the most advanced technique of retrofitting existing RC square column using stainless steel wire mesh (SSWM). It is found that the stress concentration at the corners of square column is relatively high and this reduces the efficiency of the SSWM wrapping. Therefore, the cross section of the column is converted from square to circular in order to increase the efficiency of the SSWM wrapping. This is achieved by attaching four D-section concrete covers at the four sides of the square column using a SikaHibond, Sikadur 30 LP binder. The circular column is then wrapped with a layer of SSWM whose wire thickness is $0.27 \mathrm{~mm}$. SSWM is chosen over carbon fibre reinforced polymer (CFRP) and glass fibre reinforced polymer (GFRP) in spite of their high tensile strength as their strength can't be utilised fully due to de-bonding problem. SSWM rather increases the strength, stiffness and ductility of the strengthened column.
\end{abstract}

Keywords: Square column, SSWM, D-section concrete cover, Load carrying capacity, SikaHibond, Sikadur $30 \mathrm{LP}$.

\section{INTRODUCTION}

Strengthening and retrofitting of column becomes mandatory when the load applied to the structure exceeds the design load. The increase in load is attributed due to increase in number of floors of a building or due to increase in number of vehicles in a bridge. Sometimes, the increased traffic condition does not match with the design load. The two possible alternatives to make the structure carry the increased load are reconstruction and retrofitting. Reconstruction demands more cost and time. Also vibratory force developed during the demolition of a particular structural element may cause minor or sometimes great damage to the adjacent structural elements.

The major methods practiced for strengthening of column are Plate Bonding, Steel Jacketing and RCC Jacketing. The latest developed technique in this field is Fiber Wrap Technique which is also known as Composite Fiber System. Carbon fiber reinforced polymers (CFRP) and glass fiber reinforced polymers (GFRP) are the highly used because of their high tensile strength. Epoxy resins are used for binding these to the structural columns. Though these fibers have high tensile strength, the strengthened columns do not develop much strength because of de-bonding of the wrapping.

Hence, stainless steel wire mesh (SSWM) is used as an alternative for CFRP and GFRP. Also SSWM is found to be much cheaper than CFRP and GFPR. In this experiment, the cross section of the square column is converted into circular column as the concentration of stress at the corners results in reduced efficacy of the wrapping. This study deals with the increase inpercentage load carrying capacity of the column

\section{Experimental Program}

\subsection{Summary of Experiment}

Sixteen column specimens are made and classified into two groups. These columns are made as square in cross section of area $150 \times 150 \mathrm{~mm}$ and the height is $600 \mathrm{~mm}$. All the columns are 
reinforced. The columns of first group are control columns with no external confinement of the cross section. The columns of second group are bonded with four D-section concrete covers and are wrapped with a layer of stainless steel wire mesh (SSWM). The type of the SSWM used is 40 openings per inch and the size of each opening is $380 \mu \mathrm{X} 380 \mu$. The thickness of the wire is 0.27 $\mathrm{mm}$. Once the D-section concrete cover is attached, the square column is converted into circular column and the diameter of this circularized column is $212 \mathrm{~mm}$. These columns are tested for both axial and eccentric conditions. The eccentricity given is $20 \mathrm{~mm}, 30 \mathrm{~mm}$ and $40 \mathrm{~mm}$ from the centre of the column with trial base. Two trials are made for each loading condition.

The columns of group 1 are referred as $\mathrm{C}$ representing the control column whereas the columns of group 2 are referred as $\mathrm{S}$ representing the strengthened column. The axially loaded columns are represented as 0 and the eccentrically loaded columns with trial method are represented as $20 \mathrm{~mm}$, $30 \mathrm{~mm}$ and $40 \mathrm{~mm}$ from the base of central point thus the columns are given notation as C-0, C-20, C30, C-40, S-0, S-20, S-30 and S-40.

These columns are made with M25 grade concrete and cured for 28 days. The internal reinforcement of each of the columns are made with 4 numbers of $12 \mathrm{~mm}$ bars of grade Fe 415 and 4 numbers of $8 \mathrm{~mm}$ stirrups of grade Fe 415 at a spacing of $120 \mathrm{~mm}$. The effective cover provided is $40 \mathrm{~mm}$.

\subsection{Material Tests}

The materials taken for the casting of square column are tested under laboratory conditions. The specific gravity of fine and coarse aggregates are determined using Pycnometer and are found to be 2.60 and 2.76 respectively. The specific gravity of ordinary Portland cement is determined as 3.14 using Le-Chatelier's apparatus. The average fineness modulus of coarse aggregates is found to be 0.56. The impact strength and crushing strength tests are conducted on coarse aggregates and the values are found to be $18.52 \%$ and $5.05 \%$ respectively. The standard consistency test is conducted using a Vicat's apparatus and the percentage of cement required to produce a cement paste of standard consistency is $32 \%$. The initial setting time of the cement is found as 32 minutes using the same Vicat's apparatus.

Table1. Specimen Details

\begin{tabular}{|c|c|c|c|c|}
\hline Specimen & Cross Section & External Confinement & Wrapping & Eccentricity $(\mathbf{m m})$ \\
\hline C-0 & Square & None & None & 0 \\
\hline C-20 & Square & None & None & 20 \\
\hline C-30 & Square & None & None & 30 \\
\hline C-40 & Square & None & None & 40 \\
\hline S-0 & Circle & D-section concrete cover & SSWM & 0 \\
\hline S-20 & Circle & D-section concrete cover & SSWM & 20 \\
\hline S-30 & Circle & D-section concrete cover & SSWM & 30 \\
\hline S-40 & Circle & D-section concrete cover & SSWM & 40 \\
\hline
\end{tabular}

\subsection{Specimen Construction}

The nominal mix proportion of M25 grade is 1:1:2.Based on the properties of the materials used, a mix design is generated according to IS 10262(2009): Guidelines for concrete mix design proportioning and the mix ratio acquired is 1:1.6:2.8. The concrete is prepared based on this proportion and four square columns are made in plywood moulds. The moulds are removed after 24 hours and the column specimens are cured for 28 days. For the construction of D-section concrete covers, moulds are prepared in high density thermocol. Each segmental circular concrete cover has a chord of $150 \mathrm{~mm}$ (equal to the side length of the core column section) and the central dip of the segment is $31 \mathrm{~mm}$. Totally thirty two segments are made for the eight columns of Group-S. The corners of the segments are handled with great care as they are easily subjected to damage because of their lower thickness. Each specimen in the Group-S is bonded with four segmental circular concrete covers using Sikahibond, an epoxy based two component structural bonding agent.

After the D-section concrete covers are attached to the square column and is converted into circular column, the surface of the circularized column is smoothened. Smoothening is required as the Dsection concrete covers are made in thermocol moulds. The same binding material Sikahibond is used for binding the SSWM to the column specimen. It is applied over the concrete surface and after the 
application, wrapping of SSWM is done. For practical purpose, if required, the SSWM could be covered by a layer of cement mortar for aesthetical appearance.

Fig 1 shows the cross secctional view of both square and circularized column. The reinforcement detailing is also shown in this figure. Fig 1(b) shows the circularized column and the red circle around it represents the SSWM wrapping.

Fig 2 shows the stepwise procedure for the conversion of square column into circular column i.e, the circularizing technique. Fig 2(a) shows a square column whose dimensions are $150 \mathrm{~mm} \mathrm{X} 150 \mathrm{~mm} \mathrm{X}$ $600 \mathrm{~mm}$. Fig 2(b) shows the thermocol mould which is specially cut in the shape of D-section into which concrete is poured. Fig 2(c) shows the D-section concrete cover prepared on this thermocol mould. Fig 2(d) shows the binder which is applied over the surface of the square column. Fig 2(e) shows the circularized column with D-section concrete covers on all the four sides. Fig 2(f) shows the circularized column wrapped with Stainless steel wire mesh (SSWM).

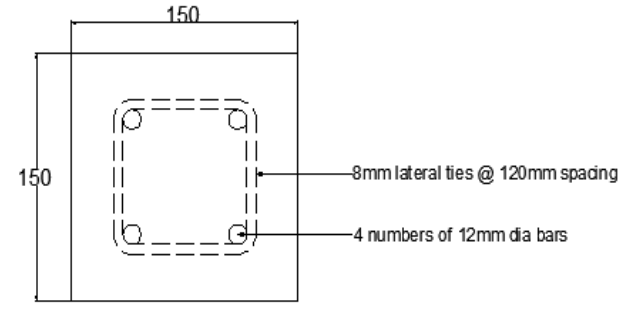

All dimensions are in $\mathrm{mm}$

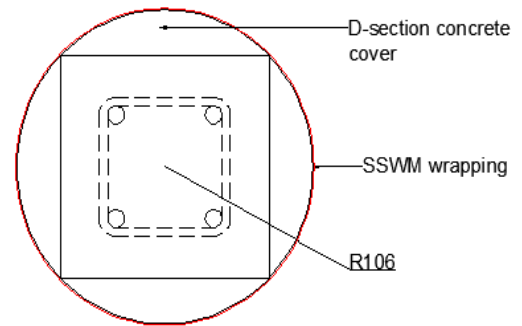

All dimensions are in $\mathrm{mm}$

b

Fig1. Cross Sectional View Of the control specimen and retrofitted RC column

\subsection{Preliminary Test}

The compressive strength of concrete are determined for 7 days and 28 days. The results are found to be 26.3 (mean value) $\mathrm{N} / \mathrm{mm}^{2}$ after 7 days of curing and 32.6 (mean value) $\mathrm{N} / \mathrm{mm}^{2}$ after 28 days of curing. Then the split tensile test in conducted on 6 standard cylindrical specimens of diameter $15 \mathrm{~mm}$ and height $30 \mathrm{~mm}$. The tensile strength of concrete after 7 days of curing is found to be $2.25 \mathrm{~N} / \mathrm{mm}^{2}$ (mean value) and after 28 days of curing it is $3.16 \mathrm{~N} / \mathrm{mm}^{2}$ (mean value).

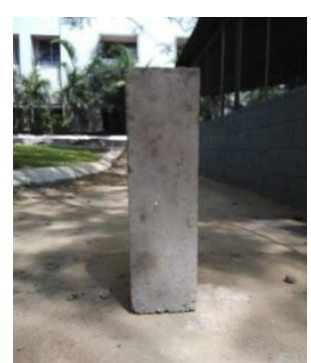

a

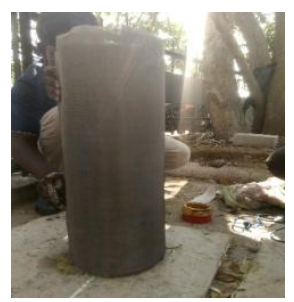

f
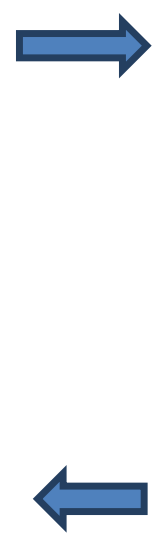

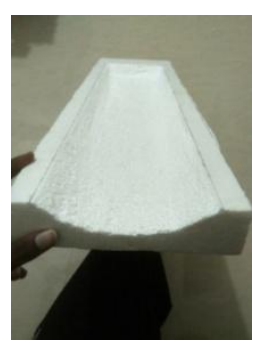

b
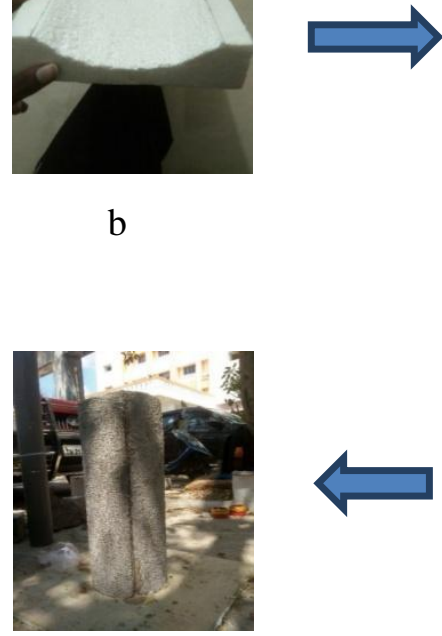

e
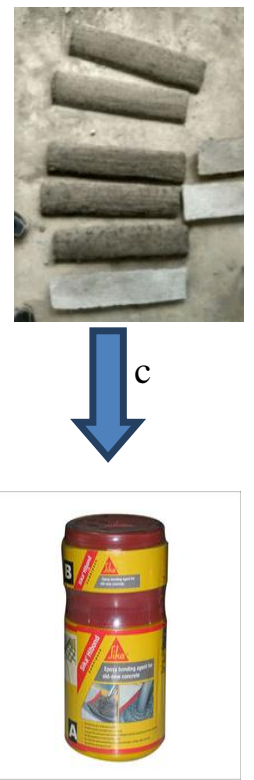

d

Fig2. Circularizing Technique fig ( $a, b, c, d, e, f)$ 


\subsection{Specimen Test}

Once the group-C specimens are cured for 28 days, they are subjected to testing. The specimens of group-S after SSWM wrapping is kept aside for 7 days The test is conducted in a Universal testing machine (UTM) of capacity $400 \mathrm{kN}$. In order to provide axial and eccentric loading, a steel plate welded with a steel rod at the centre is placed on the top of the specimens. This steel plate is adjusted according to the loading condition.

\section{RESULT AND DiSCUSSION}

\subsection{Axial Loading - Control Column}

The columns notated as C- 0 and S- 0 are tested and their results are analysed. The control column C-0 is tested first and its load carrying capacity and it's respective Deformations are noted. The deformation of column for the increasing loading conditions is carefully observed and noted. The readings are taken for every $10 \mathrm{kN}$. The deformation of the column increased with the increase in the load, after certain point there is a reduction in load and deformation as a result of the failure, the column as it reached its ultimate failure load. Column C-0 failed at trial-1 at load of $125.4 \mathrm{kN}$ with maximum deformation of $1.49 \mathrm{~mm}$ and trial-2 at $123.67 \mathrm{kN}$ with deformation of $1.43 \mathrm{~mm}$. From trial1 and trial-2, the average load carrying capacity of the column C-0 is determined as $124.56 \mathrm{KN}$ and deformation as $1.46 \mathrm{~mm}$. A graph is plotted using the load and deformation to get the behaviour of the column with load in $\mathbf{X}$-axis $(\mathbf{K N})$ and deformation in $\mathbf{Y}$-axis (mm).

\subsection{Axial Loading-Strengthened column}

Column S-0 which is the strengthened column is then tested for its deformation and behaviour. Column S-0 is tested as same as the column C-0 and its respective ultimate failure load and deformation are noted. For S-0 in trial-1the ultimate failure load is $170.7 \mathrm{KN}$ and maximum deformation is $1.79 \mathrm{~mm}$ and in trial-2 the ultimate load at failure is $167.85 \mathrm{KN}$ with a deformation of $1.81 \mathrm{~mm}$. Thus, the average load carrying capacity of the S-0 column is $169.85 \mathrm{kN}$ and the deformation is $1.80 \mathrm{~mm}$.

The load Vs deformation curve is drawn for the obtained values by plotting a graph with load and deformation in $\mathrm{X}$-axis and $\mathrm{Y}$-axis respectively. It is noted and clear from the results and the graph that due to strengthening there is a respective enhancement in the load carrying capacity of the column.

Thus, when compared with C-0 column, the strengthened S-0 column showed increase in load carrying capacity. It is also noted from the graph that the column S-0 showed greater deformation than the column C-0 but failed at higher load indicating the increase in ductility of the column S-0. Thus it is concluded that this strengthening technique not only increased the load carrying capacity of the column but also increased its ductility.

\subsection{Eccentric Loading - Control Column}

Control columns C-20, C-30, C-40 are tested and their respective ultimate failure loads and deformations are noted down. For trial-1, the ultimate failure load of column C-20 is $94.8 \mathrm{kN}$ with deformation of $0.9 \mathrm{~mm}$; the ultimate failure load of column C-30 is $87 \mathrm{kN}$ and deformation is 0.86 $\mathrm{mm}$; for column C-40 the deformation is $0.71 \mathrm{~mm}$ for an ultimate failure load of $76 \mathrm{kN}$ For trial-2 the ultimate failure load for column C-20 is $93.9 \mathrm{kNw}$ ith deformation of $0.82 \mathrm{~mm}$; for C-30 the ultimate failure load is $89 \mathrm{kN}$ with deformation of $0.85 \mathrm{~mm}$; for C-40 with deformation of $0.73 \mathrm{~mm}$, the ultimate failure load is $73.9 \mathrm{kN}$. Thus the average load carrying capacities of C-20, C-30 and C-40 are $94.35 \mathrm{kN}, 88 \mathrm{KN}$ and $74.9 \mathrm{KN}$ respectively and their average deformations are $0.96 \mathrm{~mm}, 0.85 \mathrm{~mm}$ and $0.72 \mathrm{~mm}$ respectively.

\subsection{Eccentric Loading - Strengthened Column}

After testing the control columns, the strengthened columns are tested for eccentric loading. The columns are strengthened after wrapping the stainless steel wire mesh (SSWM) around the column. Eccentric points at distance of $20 \mathrm{~mm}, 30 \mathrm{~mm}$, and $40 \mathrm{~mm}$ are marked on the strengthened column. The columns S-20, S-30, S-40 are then positioned and applied load at a constant rate. Their ultimate failure load is noted and deformation and failure modes are observed carefully. For trial-1, column S20 failed at load of $126.8 \mathrm{KN}$ with maximum deformation of $1.20 \mathrm{~mm}$, column S-30 failed at a load of 117.5 KN with maximum deformation of $1.13 \mathrm{~mm}$, and column S-40 with a failure load of $100.45 \mathrm{KN}$ and maximum deformation of $0.89 \mathrm{~mm}$. 
For trial-2, S-20 failed at a load of $123.78 \mathrm{KN}$ with maximum deformation of $1.40 \mathrm{~mm}$, for S-30 the failure load is $119.43 \mathrm{KN}$ with maximum deformation of $1.10 \mathrm{~mm}$ and $\mathrm{S}-40$ failed at $99.79 \mathrm{KN}$ with maximum deformation of $0.97 \mathrm{~mm}$. The average load carrying capacities obtained from trial-1 and trial-2 for S-20, S-30 and S-40 are $125.29 \mathrm{KN}, 118.47 \mathrm{KN}$ and $100.12 \mathrm{KN}$ respectively and the average deformation values of S-20, S-30 and S-40 are $1.30 \mathrm{~mm}, 1.12 \mathrm{~mm}$ and $0.93 \mathrm{~mm}$ respectively

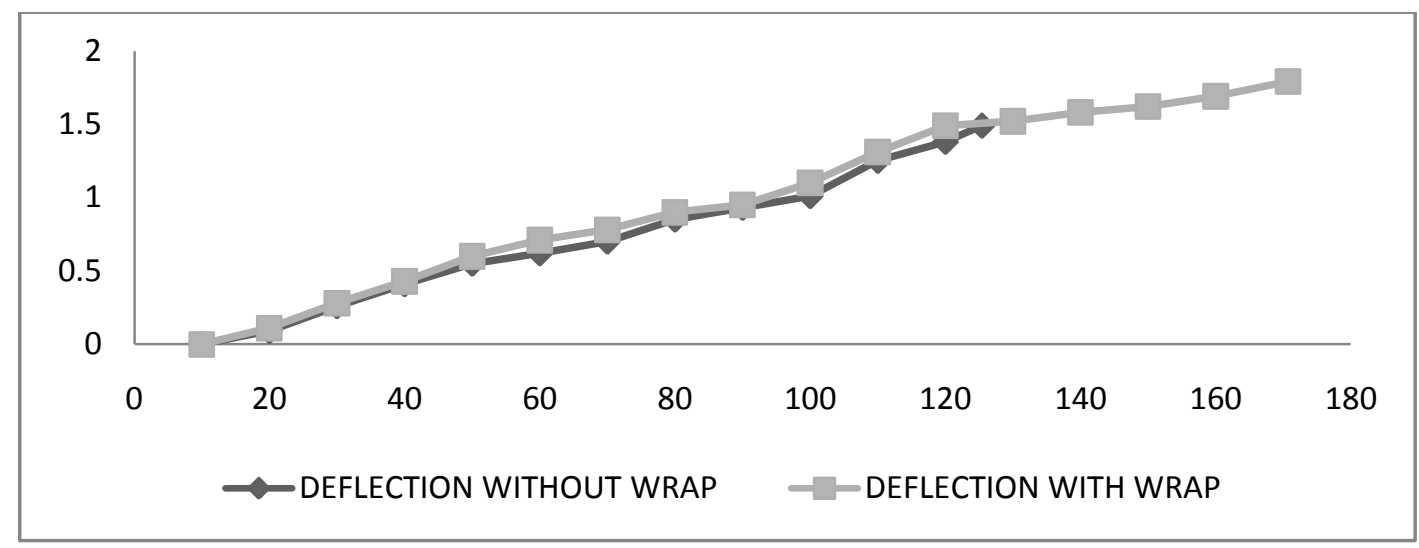

Fig3. Trial-1 for Axial Loading

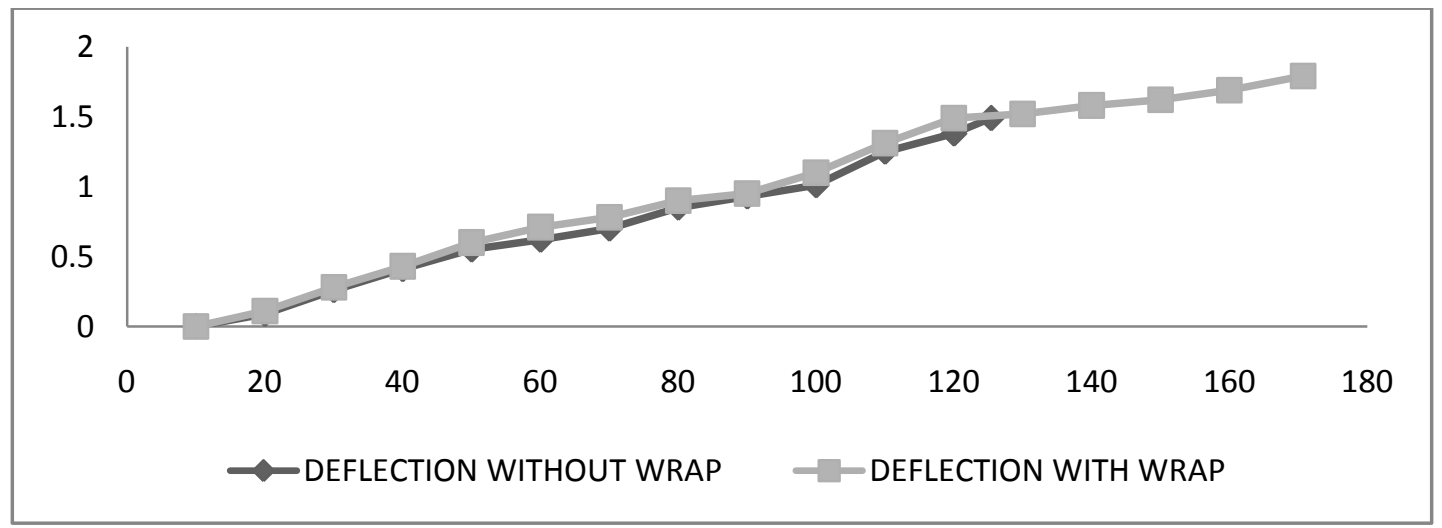

Fig4.Trial-2 for Axial Loading

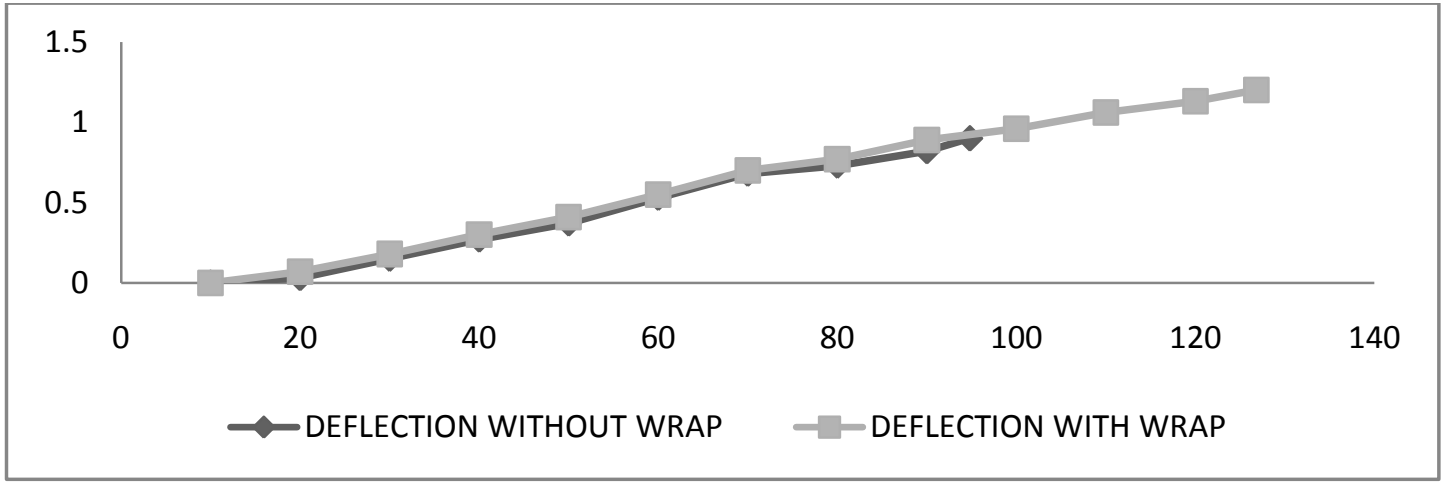

Fig5. Trial-1 for $20 \mathrm{~mm}$ Eccentric Loading

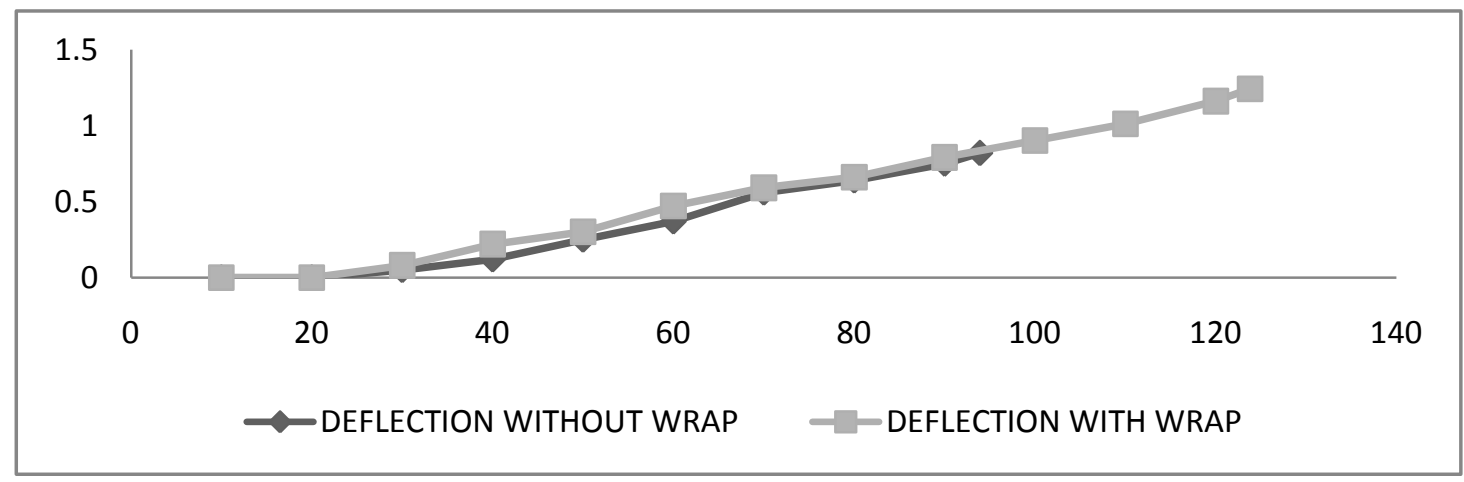

Fig6. Trial-2 for $20 \mathrm{~mm}$ Eccentric Loading 


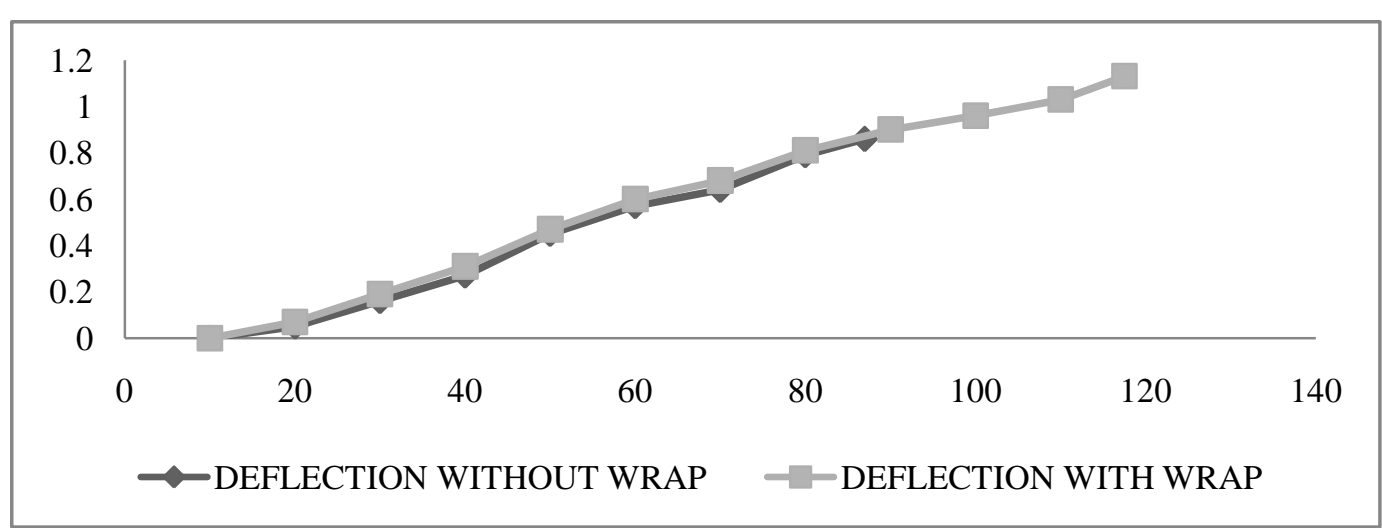

Fig7. Trial-1 for $30 \mathrm{~mm}$ Eccentric Loading

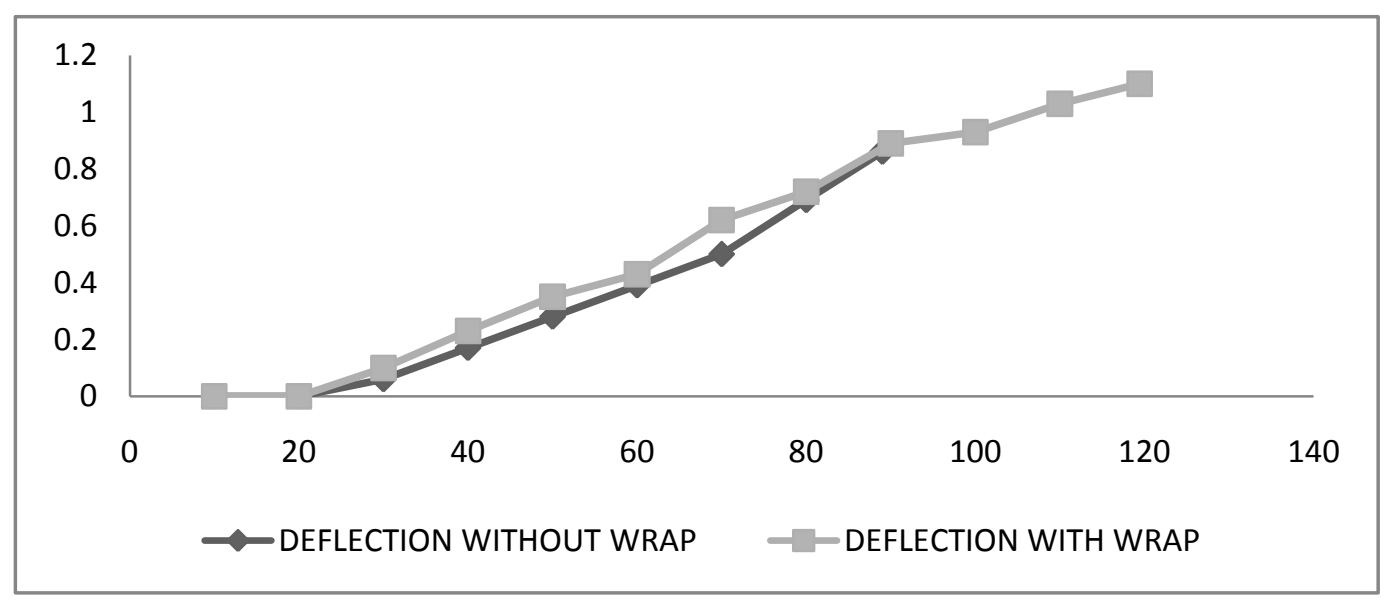

Fig8. Trial-2 for $30 \mathrm{~mm}$ Eccentric Loading

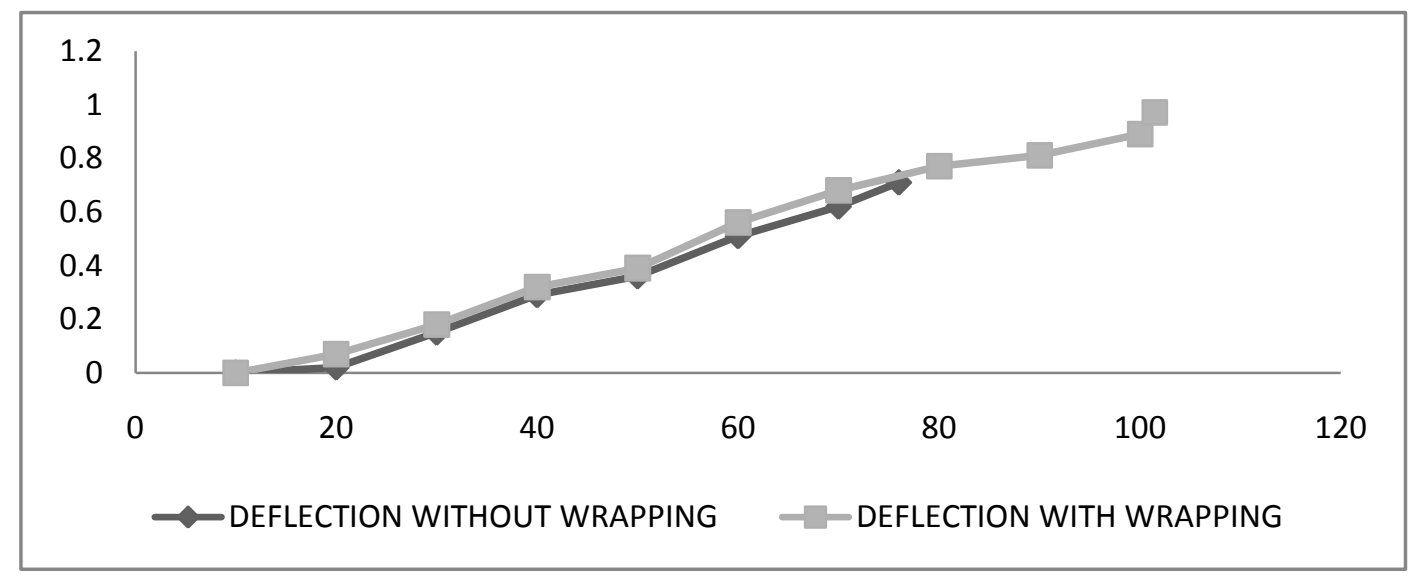

Fig9. Trial-1 for $40 \mathrm{~mm}$ Eccentric Loading

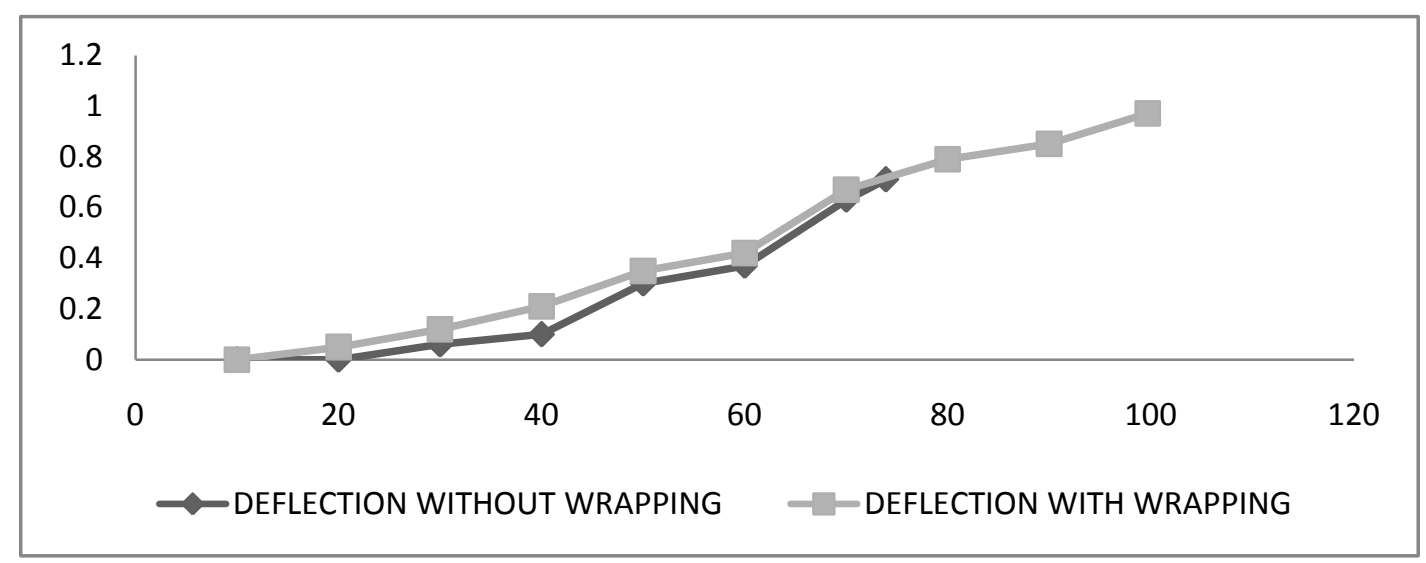

Fig10. Trial-2 for $40 \mathrm{~mm}$ Eccentric Loading 


\subsection{Failure Mode}

The control and strengthened columns showed modes of failure. The control columns developed vertical cracks which started from the point of application of axial load and extended up to full depth of specimen, when the point of application of every eccentric loading ( mention as earlier ) the failure pattern occur due to rate of loading direction. The cracks are wider in the region of load application and are reduced in width as they progress downwards. It is seen that the depth of the crack is reduced as the distance of point of application of load from the centre increases. The vertical crack that is developed in the control specimen is shown in Fig 11.

The strengthened columns showed similar vertical cracks. The cracks are also seen in the D-section concrete cover which clearly indicates the transfer of load to the D-section concrete cover showing the effectiveness of the binder. Similar to the control column, the depth of crack decreased as the distance of point of application of load from the centre increases. The SSWM wrapping also showed a breach at the top. This is due to the development of hoop stress along the circumference of the circularized column. Fig 12 shows the crack developed in the strengthened column. In order to make the crack visible, the stainless steel wire mesh wrapping is removed and the picture is taken.
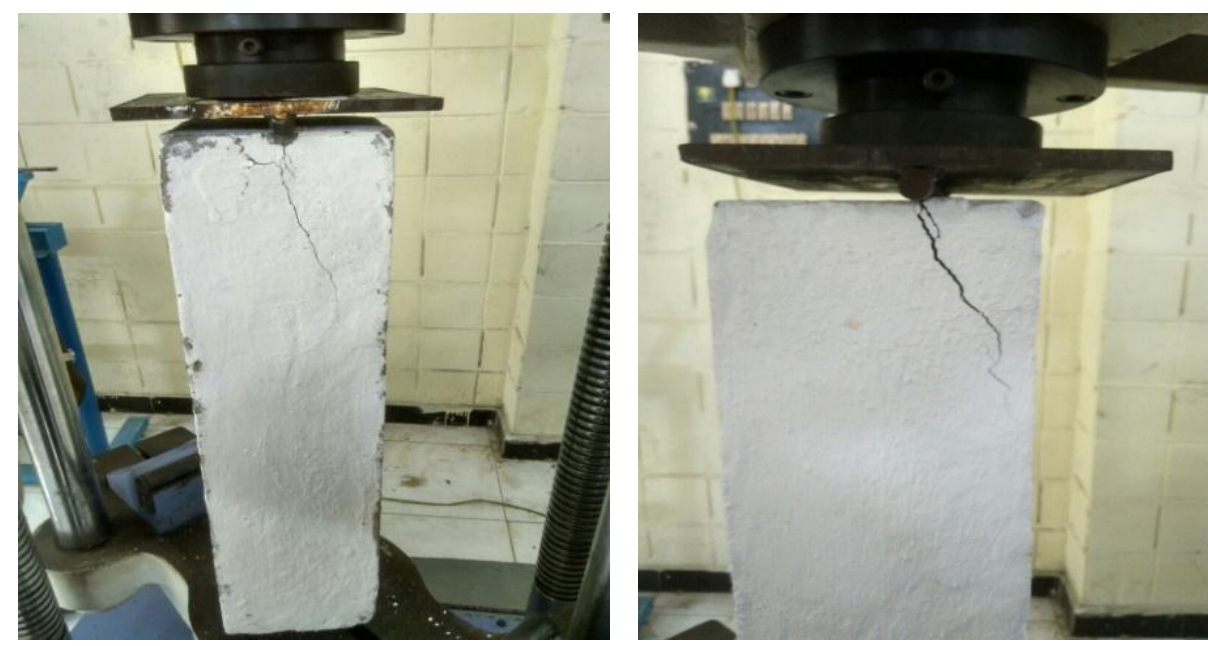

Fig11. Failure of Control Column
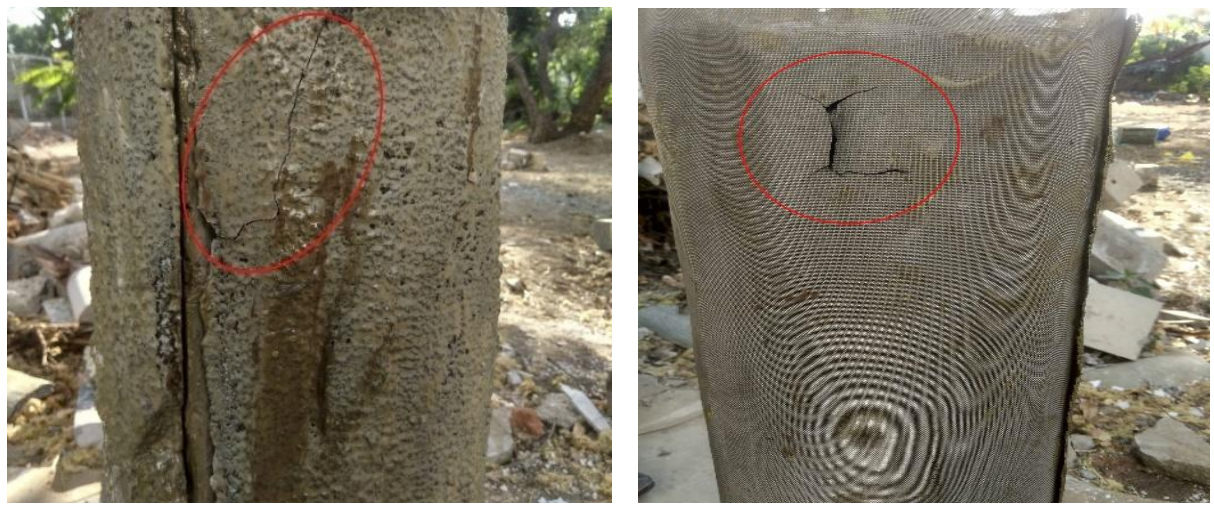

Fig12. Failure of Strengthened Column

\section{CONCLuSion}

- This method proves to increase the load carrying capacity of the strengthened column by about $30-35 \%$ without any de-bonding at any of the connections.

\begin{tabular}{|c|c|c|c|}
\hline \multirow{2}{*}{ Loading Condition } & \multicolumn{3}{|c|}{ Load (kN) } \\
\cline { 2 - 4 } & Control Specimen & Strengthened Specimen & Increase in \% \\
\hline Axial & 123.67 & 169.85 & 35.3 \\
\hline Eccentric-20mm & 94.35 & 125.29 & 32.8 \\
\hline Eccentric-30mm & 88 & 118.47 & 34.6 \\
\hline Eccentric-40mm & 74.90 & 100.12 & 33.7 \\
\hline
\end{tabular}


- The strengthened column shows increase in deformation with increase in ultimate failure load which clearly indicates the increase in ductility of the strengthened column. Thus, this technique can also be used in earthquake resistant buildings.

- Strengthened columns in this experiment compared to their unconfined counterparts exhibited a higher load-bearing capacity and a greater ductility when tested both concentrically and eccentrically.

- The circularizing technique used in this study led to more uniform confining stresses around the section circumference and it enhances confining efficiency of the SSWM wrapping.

\section{REFERENCES}

[1] IS 10262(2009): "Guidelines for concrete mix design proportioning"

[2] H. Zhao and M. N. S. Hadi, "Experimental Investigation on Using Mesh as Confinement Materials for High Strength Concrete Columns" Procedia Engineering, Volume 14, 2011

[3] Muhammad N. S. Hadi and Xu Lei, "New Method of Strengthening Reinforced Concrete Square Columns by Circularizing and Wrapping with Fiber-Reinforced Polymer or Steel Straps" Journal of Composites for Construction, Volume 17, Issue 2, April 2013.

[4] Essam S. Khalifa and Sherif H. Al-Tersawy, "Experimental and analytical behavior of strengthened reinforced concrete columns with steel angles and strips" Int J AdvStructEng, June 2014.

[5] A.M. Tarabia and H.F. Albakry, "Strengthening of RC columns by steel angles and strips" Alexanria Engineering Journal, Volume 53, Issue 3, Sep 2014.

[6] Ahmed Shaban Abdel-Hay, "Partial strengthening of R.C square columns using CFRP", HBRC Journal, Volume 10, Issue 3, Dec 2014.

[7] Alireza Saljoughian. and Davood Mostofinejad, "Corner Strip-Batten Technique for FRPConfinement of Square RC Columns under Eccentric Loading" Journal of Composites for Construction, Volume 20, Issue 3, June 2016.

[8] Varinder Kumar and P.V.Patel, "Strengthening of axially loaded circular concrete columns using stainless steel wire mesh (SSWM)" Construction and Building Materials, Volume 124, Oct 2016

\section{AUTHORS' BIOGRAPHY}

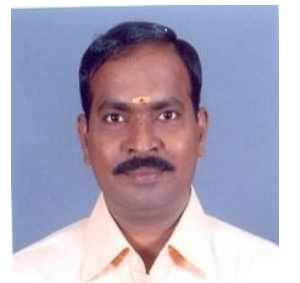

Dr. D. Elango, working as Professor \& Head in the Department of Civil Engineering at Valliammai Engineering college, Kattankulathur. He completed his post-graduation in the year 1996 and further he completed his doctoral degree at Anna University Chennai in the year 2009. He has 22 years of experience in teaching, research and consultancy. At present guiding 2 research scholars and published more than 40 papers in national and international journals \& conferences. Dr.D.Elango is a life member of ISTE and IE(I). He is editor \& reviewer in national \& international journals. He is a member, Board of studies in Civil Engineering at Anna University, Chennai.

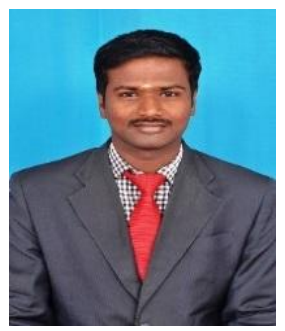

Mr. G. R. Iyappan, working as Assistant Professor in the Department of Civil Engineering at Valliammai Engineering College, Kattankulathur. He completed his post-graduation in the year 2015 with structural engineering as his field of specialization. In the area of interest is a composite structure, strengthening techniques and structural analysis. Currently he has guided a 2 UG and 1 PG projects. Mr G. R. Iyappan is a life member of ISTE.

Citation: Dr. D. Elango \& Iyappan. G.R, (2017). Strengthening of RC Square Column using Stainless Steel Wire Mesh, International Journal of Constructive Research in Civil Engineering, 3(3), pp.16-23.

Copyright: (C) 2017 Dr. D. Elango. This is an open-access article distributed under the terms of the Creative Commons Attribution License, which permits unrestricted use, distribution, and reproduction in any medium, provided the original author and source are credited 